\title{
Two New Saponins from Zygophyllum atriplicoides
}

\author{
Viqar Uddin Ahmad, ${ }^{* a}$ Shazia Iqbal, ${ }^{a}$ Farzana Kousar, ${ }^{a}$ Sadia Bader, ${ }^{a}$ Saima Arshad,,${ }^{a}$ and \\ Rasool Bakhsh TAREEN ${ }^{b}$ \\ ${ }^{a}$ HEJ Research Institute of Chemistry, International Center for Chemical Sciences, University of Karachi; 75270, Karachi, \\ Pakistan: and ${ }^{b}$ Department of Botany, Balochistan University; Quetta, Pakistan. \\ Received March 22, 2005; accepted June 11, 2005
}

\begin{abstract}
Phytochemicals investigation of the whole plant of Zygophyllum atriplicoides resulted in the isolation of two new triterpenoidal saponins together with a known compound. The structure of the new compounds atriplicosaponin A (1) and atriplicosaponin B (2) were established as 3- $O$-[ $\alpha$-D-glucopyranosyl- $(1 \rightarrow 2)-\beta$-D-xylopyranosyl]hederagenin and $27 \alpha$-hydroxyurs-12-ene-3- $O$ - $[\beta$-D-glucopyranosyl $(1 \rightarrow 4)(2-O$-sulpho)- $\beta$-D-quinovopyranoside] and known compound was identified as 3- $O$-[ $\beta$-D-glucopyranosyl]- $\beta$-sitosterol. The structure elucidations of the compounds were based primarily on $1 D$ and 2D-NMR analysis, including COSY, HMBC and HMQC correlations.
\end{abstract}

Key words Zygophyllum atriplicoides; Zygophyllaceae; triterpene glycoside; 1D-NMR spectroscopy; 2D-NMR spectroscopy

Zygophyllaceae is a family of about 25 genera and 240 species. It is distributed in tropical, subtropical and warm temperate areas. It is represented in Pakistan by 8 genera and 22 species. The genus Zygophyllum consists of about 100 species, distributed in deserts and steppes from Mediterranean to Central Asia, South Africa and Australia. In Pakistan it is found in the Sindh and Balochistan provinces. ${ }^{1)}$ The genus Zygophyllum represents the largest genus in the family Zygophyllaceae. ${ }^{2)}$

Some of the plants belonging to genus Zygophyllum are used in folk medicine. Leaves, stems and fruits of Zygophyllum coccineum are used as the drug 'Kammun Quaramany'. This drug is active against rheumatism, gout, asthma and hypertension and is also used as a diuretic, antihelmenthic and antidiabietic agent. ${ }^{3)}$ Extracts from Zygophyllum dumosum (Borss.) are used in Egypt to treat rheumatism, gout, asthma and hypertension. ${ }^{2)}$ The leaf juice of Zygophyllum simplex acts as a skin cleanser. It was also reported for the horny patches on skin in the North Africa and Arabia region. $\left.{ }^{4}\right)$

In a previous investigation quinovic acid, saponins and tannins have been found in the leaves, stem and roots of $Z y$ gophyllum coccineum. ${ }^{3)}$

Our current study led to the isolation of two new triterpenoidal saponin with the known constituent 3- $O$ - $[\beta$-D-glucopyranosyl]- $\beta$-sitosterol which was first time isolated from this plant. Herein, we describe their isolation and structure elucidation.

\section{Results and Discussion}

The $\mathrm{BuOH}$-soluble fraction (see experimental) yielded compounds 1, 2 and 3 . Compound 1, was purified by repeated column chromatography on silica gel $60(70-230$ mesh size) using solvent system $\mathrm{MeOH}: \mathrm{CHCl}_{3}(18: 82)$ by recrystallization from methanol, compound $\mathbf{2}$, by $\mathrm{MeOH}: \mathrm{CHCl}_{3}(20: 80)$ and compound 3, by $\mathrm{MeOH}: \mathrm{CHCl}_{3}$ $(16: 84)$.

The UV spectrum in methanol showed a sharp peak at $199 \mathrm{~nm}$ as end absorption. In the IR spectrum the compound 1 showed peaks at $3400(\mathrm{OH})$ and $1700(\mathrm{COOH}) \mathrm{cm}^{-1}$. The ${ }^{13} \mathrm{C}$-NMR spectrum summarized in Table 1 was assigned on the basis of broad band (BB), distortion less enhancement by polarization transfer (DEPT), and heteronuclear multiple quantum coherence (HMQC) experiments. The appearance of the two anomeric carbon resonated at $\delta 103.90$ and $\delta$ 106.01 suggested the presence of two monosaccharide moieties. The ${ }^{13} \mathrm{C}$-NMR spectrum of $\mathbf{1}$ showed the presence of 41 carbon atoms in the molecule 11 carbon signals were seen for the sugar moieties, confirming the presence of one hex-
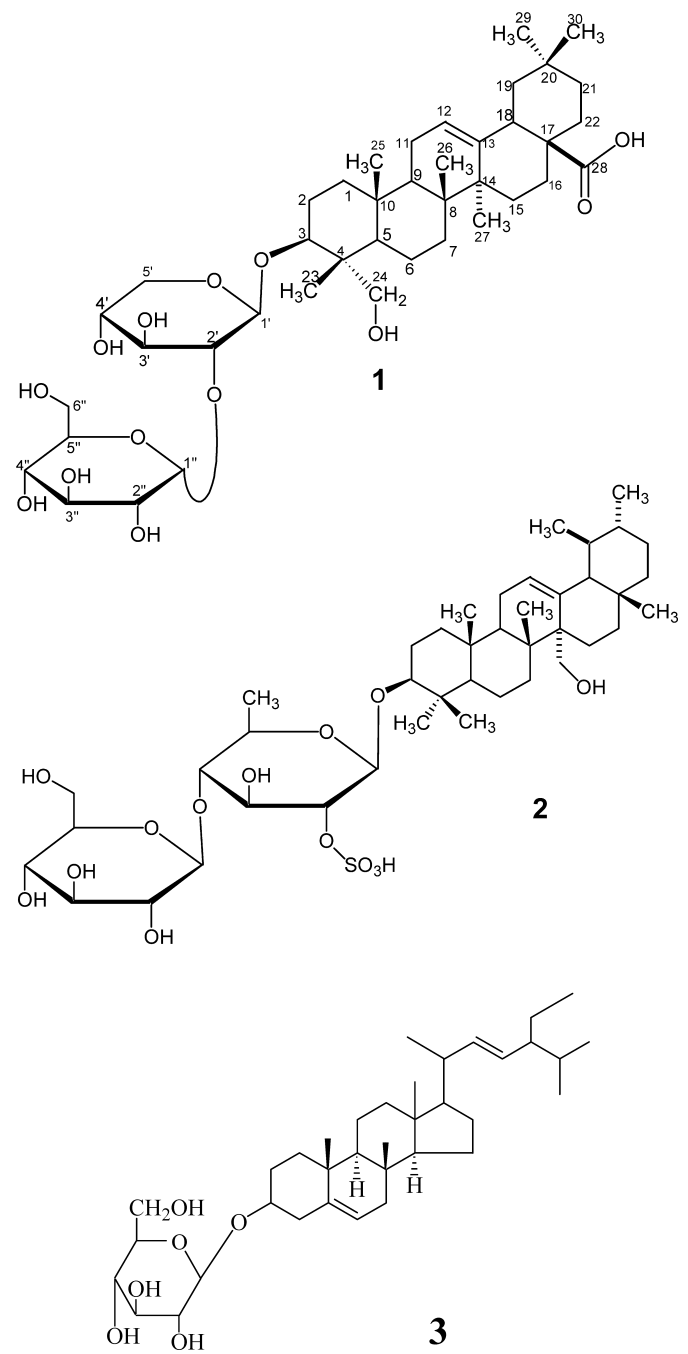

Fig. 1. Triterpenoidal Saponins from Zygophyllum atriplicoides 
Table 1. ${ }^{1} \mathrm{H}$ - and ${ }^{13} \mathrm{C}-\mathrm{NMR}$ Data for Compounds $\mathbf{1}$ and $\mathbf{2}$

\begin{tabular}{|c|c|c|c|c|}
\hline & \multicolumn{2}{|l|}{1} & \multicolumn{2}{|l|}{2} \\
\hline & $\left.\delta_{\mathrm{H}} \operatorname{multi}(J \text { in } \mathrm{Hz})^{a}\right)$ & $\delta_{\mathrm{C}}^{b)}$ & $\delta_{\mathrm{H}} \operatorname{multi}(J \text { in } \mathrm{Hz})^{c)}$ & $\left.\delta_{\mathrm{C}}{ }^{d}\right)$ \\
\hline \multicolumn{5}{|c|}{ The aglycone moiety } \\
\hline 1 & $1.26,1.88$ & 38.78 & $1.45,1.87$ & 38.07 \\
\hline 2 & $1.52,1.64$ & 26.16 & $1.86,1.95$ & 23.86 \\
\hline 3 & $3.60 \mathrm{dd}(11.0,4.5)$ & 80.74 & $3.05 \mathrm{~m}$ & 91.36 \\
\hline 4 & 43.54 & & & 39.10 \\
\hline 5 & 1.22 & 48.17 & 0.64 & 55.75 \\
\hline 6 & $1.63,1.25$ & 18.26 & $1.32,1.46$ & 19.30 \\
\hline 7 & $1.25,1.30$ & 34.26 & $1.25,1.42$ & 31.41 \\
\hline 8 & & 42.02 & & 38.40 \\
\hline 9 & 2.12 & 49.68 & 1.80 & 49.85 \\
\hline 10 & & 36.98 & & 40.15 \\
\hline 11 & $2.60,3.42$ & 23.89 & $2.44,2.32$ & 25.92 \\
\hline 12 & $5.46 \mathrm{dt}$ & 121.08 & $5.61 \mathrm{~m}$ & 129.95 \\
\hline 13 & & 148.74 & & 134.44 \\
\hline 14 & & 42.20 & & 40.65 \\
\hline 15 & $1.44,1.46$ & 28.38 & $1.68,1.88$ & 27.02 \\
\hline 16 & $2.28,2.32$ & 23.80 & $2.29,2.31$ & 30.61 \\
\hline 17 & & 46.68 & & 34.11 \\
\hline 18 & 3.65 & 41.30 & 2.25 & 56.83 \\
\hline 19 & $1.92,1.98$ & 48.01 & $1.60,1.65$ & 37.35 \\
\hline 20 & & 32.94 & & 38.62 \\
\hline 21 & $1.45,1.47$ & 36.98 & $1.25,1.42$ & 32.25 \\
\hline 22 & $1.22,1.24$ & 30.96 & $1.01,1.65$ & 39.25 \\
\hline \multirow[t]{2}{*}{23} & $4.12 \mathrm{~d}(10.1)$ & 65.01 & $0.92 \mathrm{~s}$ & 28.10 \\
\hline & $4.22 \mathrm{~d}(10.1)$ & & & \\
\hline 24 & $1.39 \mathrm{~s}$ & 13.45 & $1.03 \mathrm{~s}$ & 19.24 \\
\hline 25 & $1.26 \mathrm{~s}$ & 16.08 & $0.76 \mathrm{~s}$ & 16.89 \\
\hline 26 & $1.38 \mathrm{~s}$ & 17.48 & $0.86 \mathrm{~s}$ & 18.04 \\
\hline \multirow[t]{2}{*}{27} & $1.45 \mathrm{~s}$ & 25.96 & $3.58 \mathrm{~d}(11.0)$ & 64.29 \\
\hline & & & $3.45 \mathrm{~d}(11.0)$ & \\
\hline 28 & & 180.00 & 0.96 & 17.05 \\
\hline 29 & $1.30 \mathrm{~s}$ & 33.25 & $1.00 \mathrm{~d}(6.0)$ & 21.58 \\
\hline 30 & $1.34 \mathrm{~s}$ & 24.46 & $1.05 \mathrm{~d}(6.0)$ & 25.30 \\
\hline \multicolumn{5}{|c|}{ 3-O- $\beta$-D-Xylopyranosyl } \\
\hline $1^{\prime}$ & $5.60 \mathrm{~d}(7.22)$ & 106.01 & & \\
\hline $2^{\prime}$ & 4.59 & 82.30 & & \\
\hline $3^{\prime}$ & 4.57 & 79.74 & & \\
\hline $4^{\prime}$ & 4.72 & 68.29 & & \\
\hline $5^{\prime}$ & $4.10,4.22$ & 65.51 & & \\
\hline \multicolumn{5}{|c|}{ 2-O- $\alpha$-D-Glucopyranosyl } \\
\hline $1^{\prime \prime}$ & $5.45 \mathrm{~d}(3.78)$ & 103.90 & & \\
\hline $2^{\prime \prime}$ & 4.62 & 76.28 & & \\
\hline $3^{\prime \prime}$ & 4.58 & 78.31 & & \\
\hline $4^{\prime \prime}$ & 4.56 & 71.47 & & \\
\hline $5^{\prime \prime}$ & 4.64 & 79.74 & & \\
\hline $6^{\prime \prime}$ & $4.18,4.20$ & 62.60 & & \\
\hline \multicolumn{5}{|c|}{ 3-O- $\beta$-D-Quinovopyranosyl } \\
\hline $1^{\prime}$ & & & $4.41 \mathrm{~d}(7.62)$ & 104.04 \\
\hline $2^{\prime}$ & & & 4.15 & 82.11 \\
\hline $3^{\prime}$ & & & 3.58 & 77.51 \\
\hline $4^{\prime}$ & & & 3.38 & 78.20 \\
\hline $5^{\prime}$ & & & 3.55 & 70.93 \\
\hline $6^{\prime}$ & & & $1.25 \mathrm{~d}(6.06)$ & 18.28 \\
\hline \multicolumn{5}{|c|}{ 2- $O-\beta$-D-Glucopyranosyl } \\
\hline $1^{\prime \prime}$ & & & $4.45 \mathrm{~d}(7.72)$ & 104.75 \\
\hline $2^{\prime \prime}$ & & & 3.45 & 75.24 \\
\hline $3^{\prime \prime}$ & & & 3.32 & 77.26 \\
\hline $4^{\prime \prime}$ & & & 3.20 & 72.60 \\
\hline $5^{\prime \prime}$ & & & 4.03 & 78.52 \\
\hline $6^{\prime \prime}$ & & & $3.78,3.80$ & 65.87 \\
\hline
\end{tabular}

a) $500 \mathrm{MHz}$ for $\left.{ }^{1} \mathrm{H}, b\right) 125 \mathrm{MHz}$ for ${ }^{13} \mathrm{C}$ in $\mathrm{C}_{5} \mathrm{D}_{5} \mathrm{~N}$, for compound 1. c) $300 \mathrm{MHz}$ for $\left.{ }^{1} \mathrm{H}, d\right) 75 \mathrm{MHz}$ for ${ }^{13} \mathrm{C}$ in $\mathrm{CD}_{3} \mathrm{OD}$ for compound 2 . The ${ }^{1} \mathrm{H}$ and ${ }^{13} \mathrm{C}$ chemical shifts were assigned by a combination of ${ }^{1} \mathrm{H}-{ }^{1} \mathrm{H}$ COSY, HMQC and HMBC experiments. ose and one pentose, the remaining 30 carbon signals were due to triterpenoid aglycone. The broad band ${ }^{13} \mathrm{C}$-NMR spectrum showed the presence of 6 methyl, 13 methylene, 14 methine and 8 quarternary carbon atoms in agreement with structure 1. The downfield ${ }^{13} \mathrm{C}-\mathrm{NMR}$ chemical shift at $\delta$ 80.74 suggested that the disaccharide moiety was attached to the $\mathrm{C}-3$ of the aglycone ${ }^{5)}$ and it was further confirmed by heteronuclear multiple bond connectivity (HMBC) correlation of anomeric protons with $\mathrm{C}-3$. The occurrence of the olefinic carbon signals at $\delta 121.08$ and $\delta 148.74$ corresponding to methine and quaternary carbons, suggested the presence of endocyclic double bond at the 12-position in an oleanane skeleton. ${ }^{6}$ Moreover, the ${ }^{13} \mathrm{C}-\mathrm{NMR}$ data were analyzed by analogy with the reported data of oleanane triterpenoid which led to the identification of the aglycone as hederagenin. 5,7 )

The structure of compound 1 was further supported by ${ }^{1} \mathrm{H}-$ NMR and negative ion FAB mass spectra. The ${ }^{1} \mathrm{H}-\mathrm{NMR}$ spectrum of 1 indicated the presence of six tertiary methyl singlets for C-24, C-25, C-26, C-27, C-29 and C-30 at $\delta$ $1.39,1.26,1.38,1.45,1.30$ and 1.34 respectively. The $\mathrm{H}-3$ of carbinylic proton resonated at $\delta 3.60$. The ${ }^{1} \mathrm{H}-\mathrm{NMR}$ spectrum also showed the presence of an olefinic proton resonance as a distorted triplet at $\delta 5.46$ characteristic for the $\mathrm{H}$ 12 in pentacyclic triterpenes. ${ }^{8)}$

The analysis of $1 \mathrm{D}$ and 2D-NMR spectra revealed that the carbon signal at 180.0 indicated the presence of free carboxyl group at $\mathrm{C}-17$. In the $\mathrm{HMBC}$ spectrum, $\mathrm{C}-17$ was correlated with a proton signal at C-16 $(\delta 2.28,2.32), \mathrm{C}-18(\delta 3.65)$ and $\mathrm{C}-22(\delta 1.22,1.24)$. It was further confirmed by methylation of compound $\mathbf{1}$ to its methyl ester, supported by a peak at $m / z 486$ in EI-MS. In a NOESY spectrum, the presence of a cross-peak between $\mathrm{H}-24$ and $\mathrm{H}-25$ indicated that the methyl group at C-24 was axially; which in turn suggested a $\alpha$-configuration for the hydroxymethyl at $\mathrm{C}-24$. The ${ }^{1} \mathrm{H}$ NMR spectrum indicated the presence of two sugar moieties. The anomeric proton at $\delta 5.45(\mathrm{~d}, J=3.78 \mathrm{~Hz})$ showed the $\alpha$ configuration for D-glucose and at $\delta 5.60(\mathrm{~d}, J=7.22 \mathrm{~Hz})$ showed the $\beta$-configuration for $\mathrm{D}$-xylose moiety. The ${ }^{1} \mathrm{H}$ NMR assignments were confirmed with the help of $2 \mathrm{D}-J$ resolved, COSY $45^{\circ}$ and NOESY experiments. A molecular weight of 766 was confirmed by an intense peak at $\mathrm{m} / \mathrm{z} 765$ in the negative ion FAB-MS of the compound $\mathbf{1}$ which is due to $[\mathrm{M}-\mathrm{H}]^{-}$ion, corresponding to the molecular formula $\mathrm{C}_{41} \mathrm{H}_{66} \mathrm{O}_{13}$ indicating the degree of unsaturation as 9 double bond equivalents. Furthermore, negative fragment ion at $m / z$ 603 may be ascribed respectively to the loss of a terminal glucose unit. A second fragment ion at $\mathrm{m} / \mathrm{z} 455$ may be attributed to the loss, from the $[\mathrm{M}-\mathrm{H}]^{-}$ion, of a glucose-xylose disaccharide unit. This sequence indicated that the terminal glucose moiety was linked to xylose. This, in turn, was attached to the $\mathrm{C}-3$ of hederagenin. This fragmentation also showed that both the sugars of compound 1 were linked to each other by inter-glycosidic linkages as determined by ${ }^{13} \mathrm{C}$ NMR data.

The acid hydrolysis of compound $\mathbf{1}$ yielded the aglycone that was identified as hederagenin by comparing with spectral and physical data reported in the literature.9,10) The sugars obtained from hydrolysates were identified as glucose and xylose. The $J$-values and ${ }^{13} \mathrm{C}$-NMR spectral data deduced the $\beta$-D-pyranosyl configuration for xylose and $\alpha$-D-pyranosyl 
configuration for glucose. ${ }^{11)}$

The points of attachment of sugar units were determined through ${ }^{13} \mathrm{C}$-chemical shifts in which the upfield shifts of $\beta$ carbons and the downfield shift of $\alpha$-carbons were characteristic for the establishment of interglycosidic linkages. ${ }^{12)}$

The signal at $\delta 82.30$ corresponding to the $\mathrm{C}-2^{\prime}$ of the xylose moiety is indicative of a disaccharide in which the xylosyl group is attached to the aglycone and has a second glucosyl unit attached at C-2' which was further confirmed by the strong HMBC interaction of $\delta 5.45 \mathrm{H}^{\prime \prime} 1^{\prime \prime}$ of glucose to $\delta$ 82.30 ppm C-2' of xylose. ${ }^{13)}$

One bond correlation between ${ }^{1} \mathrm{H}$ - and ${ }^{13} \mathrm{C}$-nuclei were established by HMQC experiments, ${ }^{14)}$ which provided conclusive evidence to establish the structure of compound $\mathbf{1}$. The signals of C-3, C-11, C-12 and C-15 in the ${ }^{13} \mathrm{C}-\mathrm{NMR}$ spectrum at $\delta 80.74,23.89,121.08$ and 28.38 could be easily correlated with corresponding protons in the ${ }^{1} \mathrm{H}-\mathrm{NMR}$ spectrum at $\delta 3.60,2.60,3.42,5.46,1.44$ and 1.46 . The methyl carbons resonated at $\delta 13.45(\mathrm{C}-24), 16.08(\mathrm{C}-25), 17.48(\mathrm{C}$ 26), 25.96 (C-27), 33.25 (C-29) and 24.46 (C-30) respectively. These carbons are coupled with protons at $\delta 1.39$, $1.26,1.38,1.45,1.30$ and 1.34 , respectively in the HMQC spectrum. The anomeric carbons $\mathrm{C}-1^{\prime}$ and $\mathrm{C}-1^{\prime \prime}$ were coupled to the proton resonating at $\delta 5.60$ and 5.45 which confirmed that these proton signals were due to $\mathrm{H}-1^{\prime}$ and $\mathrm{H}-1^{\prime \prime}$, respectively.

The 2D homonuclear ${ }^{1} \mathrm{H}-{ }^{1} \mathrm{H}$ chemical shift correlation $\left(\mathrm{COSY}-45^{\circ}\right)^{14)}$ which illustrated the proton connectivity (Fig. 2) provided further insights into the structure 1 . The position of double bond at C-12 was finally confirmed by COSY- $45^{\circ}$ which showed the connectivity of $\mathrm{H}-11(\delta 2.60)$ to vinylic $\mathrm{H}-$ $12(\delta 5.46)$.

Finally, on the basis of all the above evidences the structure of 1 was established as 3-O-[ $\alpha$-D-glucopyranosyl$(1 \rightarrow 2)-\beta$-D-xylopyranosyl] hederagenin.

In compound 2 the UV spectrum in methanol showed a sharp peak at $195.8 \mathrm{~nm}$ as end absorption. In the IR spectrum the compound 2 showed peaks at $3449.7(\mathrm{OH}), 2926(\mathrm{CH})$, $2854(\mathrm{C}=\mathrm{C})$ and $1256(\mathrm{C}-\mathrm{O}) \mathrm{cm}^{-1}$. The ${ }^{13} \mathrm{C}-\mathrm{NMR}$ spectrum summarized in Table 1 was assigned on the basis of $\mathrm{BB}$, DEPT and HMQC experiments. The appearance of the two anomeric carbon resonated at $\delta 104.75$ and $\delta 104.04$ suggested the presence of two monosaccharide moieties. The ${ }^{13} \mathrm{C}-\mathrm{NMR}$ spectrum of 2 showed the presence of 42 carbon atoms in the molecule 12 carbon signals were seen for the sugar moieties, confirming the presence of two hexoses, the remaining 30 carbon signals were due to triterpenoidal aglycone. The broad band ${ }^{13} \mathrm{C}-\mathrm{NMR}$ spectrum showed the presence of 8 methyl, 11 methylene, 17 methine and 6 quarternary carbon atoms in agreement with structure 2 . The downfield ${ }^{13} \mathrm{C}$ chemical shift at $\delta 91.36$ showed that the disaccharide moiety was attached to the C-3 of the aglycone. ${ }^{15}$ ) The occurrence of the olefinic carbon signals at $\delta 129.95$ and $\delta 134.44$ corresponding to methine and quaternary carbons, suggested the presence of endocyclic double bond at the 12position in an ursane skeleton. The presence of hydroxymethyl at C-27 was confirmed by its HMBC correlation with $\mathrm{C}-13$ and $\mathrm{C}-14$. Moreover, the ${ }^{13} \mathrm{C}-\mathrm{NMR}$ data were analyzed by analogy with the reported data of 27-hydroxyursane triterpenoid which led to the identification of the aglycone. ${ }^{16)}$

The structure of compound 2 was further supported by ${ }^{1} \mathrm{H}-$

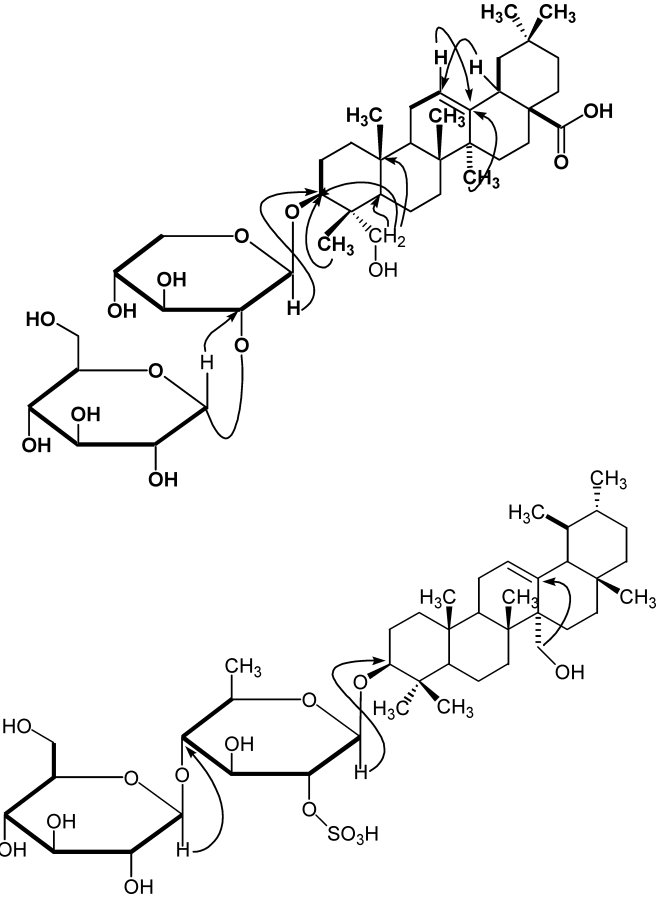

Fig. 2. Selected HMBC and COSY Correlation of $\mathbf{1}$ and $\mathbf{2}$

$\mathrm{COSY} \longrightarrow, \mathrm{HMBC} \longrightarrow$

NMR and positive ion FAB mass spectra. The ${ }^{1} \mathrm{H}-\mathrm{NMR}$ spectrum of 2 indicated the presence of five tertiary methyl singlets for C-23, C-24, C-25, C-26 and C-28 at $\delta 0.92,1.03$, $0.76,0.86$ and 0.96 . Two secondary methyls C-29 and C-30 at $\delta 1.00$ and 1.05 respectively. The attachment of carbinylic proton of $\mathrm{H}-3$ resonated at $\delta 3.05 .{ }^{15)}$ The ${ }^{1} \mathrm{H}-\mathrm{NMR}$ spectrum also showed the presence of an olefinic proton resonated as a distorted triplet at $\delta 5.61$ characteristic for the H-12 in pentacyclic triterpenes. ${ }^{8)}$ The ${ }^{1} \mathrm{H}-\mathrm{NMR}$ spectrum also indicated the presence of two sugar moieties. This saponin contains a $-\mathrm{SO}_{3} \mathrm{H}$ group linked to the $2-O$ - of $\beta$-D-quinovopyranosyl moiety. This type of saponin was previously reported in Zygophyllum propinquum and Zygophyllum album. ${ }^{3)}$ The anomeric proton at $4.45(\mathrm{~d}, J=7.72 \mathrm{~Hz})$ showed the $\beta$-configuration for $\mathrm{D}$-glucose. The anomeric signal of the $\beta-O$ quinovopyranosyl moiety, appeared at $\delta 4.41(\mathrm{~d}, J=7.62 \mathrm{~Hz})$. A doublet at $\delta 1.25(\mathrm{~d}, J=6.06 \mathrm{~Hz})$ was due to the methyl signal of the quinovose moiety. The downfield shifts of the $\mathrm{H}-2^{\prime}(\Delta \delta+1.00)$ and $\mathrm{C}-2^{\prime}(\Delta \delta+5.3)$ signals compared with those of quinovose indicate that the sulphate group is in position $\mathrm{C}-2^{\prime}$ of the quinovose. A molecular weight of 831 was confirmed by an intense peak at $\mathrm{m} / \mathrm{z} 832$ in the positive ion FAB-MS of the compound 2 which is due to $[\mathrm{M}+\mathrm{H}]^{+}$ion, corresponding to the molecular formula $\mathrm{C}_{42} \mathrm{H}_{70} \mathrm{O}_{14} \mathrm{~S}$. Furthermore, positive fragment ion at $m / z 668$ may be ascribed to the loss of a terminal glucose unit. A second fragment ion at $\mathrm{m} / \mathrm{z} 442$ may be attributed to the loss, from the $[\mathrm{M}+\mathrm{H}]^{+}$ion, of a glucose-quinovose disaccharide unit. This sequence indicated that the terminal glucose moiety was linked to quinovose. This, in turn, was attached to the C-3 of compound 2. This fragmentation also showed that both sugars were linked to each other by inter-glycosidic linkages as determined by ${ }^{13} \mathrm{C}$-NMR data.

The acid hydrolysis of compound $\mathbf{2}$ yielded the aglycone 
that was identified as 27-hydroxyursane by comparing with spectral and physical data reported in the literature. $\left.{ }^{15}\right)$ The sugars obtained from hydrolysates were identified as glucose and quinovose. The ${ }^{13} \mathrm{C}-\mathrm{NMR}$ spectral data deduced the $\beta$-Dpyranosyl configuration for glucose and quinovose.

The signal at $\delta 78.20$ corresponding to the $\mathrm{C}-4^{\prime}$ of the quinovose moiety is indicative of a disaccharide in which the quinovose group is attached to the aglycone and has a second glucosyl unit attached at C-4' which was further confirmed by the strong HMBC interaction of $\delta 4.45 \mathrm{H}-1^{\prime \prime}$ of glucose to $\delta 78.20 \mathrm{C}-4^{\prime}$ of quinovose.

The signals of C-3, C-11, C-12 and C-15 in the ${ }^{13} \mathrm{C}-\mathrm{NMR}$ spectrum at $\delta 91.36,25.92,129.95$ and 27.02 could be easily correlated with corresponding protons in the ${ }^{1} \mathrm{H}-\mathrm{NMR}$ spectrum at $\delta 3.05,2.32,2.44,5.61,1.68$ and 1.88 which were shown by HMQC. ${ }^{11)}$ The methyl carbons resonated at $\delta$ 28.10 (C-23), 19.24 (C-24), 16.89 (C-25), 18.04 (C-26), 28.52 (C-28), 17.05 (C-29) and 21.58 (C-30) respectively. These carbons are coupled with protons at $\delta 0.92,1.03,0.76$, $0.86,0.96,1.00$ and 1.05 . The anomeric carbons $\mathrm{C}-1^{\prime}$ and $\mathrm{C}$ $1^{\prime \prime}$ were coupled to the proton resonating at $\delta 4.41$ and $\delta 4.45$ which confirmed that these proton signals were due to $\mathrm{H}-\mathrm{1}^{\prime}$ and $\mathrm{H}-\mathrm{1}^{\prime \prime}$, respectively.

The position of double bond at $\mathrm{C}-12$ was finally confirmed by $\operatorname{COSY}-45^{\circ}$ which showed the connectivity of H-11 ( $\delta$ $2.32)$ to vinylic $\mathrm{H}-12(\delta 5.61)$.

Finally, on the basis of all the above accumulated evidences the structure of $\mathbf{2}$ was established as $27 \alpha$-hydroxyurs12 -ene-3-O-[ $\beta$-D-glucopyranosyl $(1 \rightarrow 4)(2-O$-sulpho $)-\beta$-Dquinovopyranoside].

Compound 3 showed a $[\mathrm{M}-\mathrm{H}]^{-}$ion peak at $\mathrm{m} / z 575$ in the negative ion FAB mass spectrum. The fragment which appeared at $\mathrm{m} / \mathrm{z} 413$ showed the loss of a hexose moiety. The acid hydrolysis of $\mathbf{3}$ yielded a sapogenin which was identified as a $\beta$-sitosterol by comparing with spectral data reported in the literature. ${ }^{16)}$ The sugar obtained from the hydrolysate was identified as glucose on silica gel TLC by comparing with an authentic sample. The anomeric signal appeared at $\delta 4.57$ (d, $J=7.96 \mathrm{~Hz}$ ) $\beta$-D-pyranosyl configuration for glucose. Hence, on the above evidence 3 was identified as 3-O-[ $\beta$-D-glucopyranosyl]- $\beta$-sitosterol.

\section{Experimental}

General Experimental Methods Column chromatography (CC): silica gel, $70-230$ mesh. Flash chromatography (FC): silica gel 230-400 mesh. TLC was carried out on E. Merck silica gel plates using the indicated solvents: $\mathrm{CHCl}_{3}: \mathrm{MeOH}=75: 25 \quad \mathrm{BAW}=12: 3: 5$ butanol-AcOH-water; $\mathrm{BEW}=12: 3: 5$ butanol-EtOH-water and detected by ceric sulphate reagent. The IR and UV-Spectra were recorded on a Jasco-320-A and Hitachi-UV-240, respectively. Optical rotation was recorded on Jasco DIP-360, Digital Polarimeter. Fast atomic bombardment mass spectra (FAB-MS) were recorded on a double focusing Varian MAT-312 spectrometer. ${ }^{1} \mathrm{H}-$ and ${ }^{13} \mathrm{C}$ NMR, COSY, HMQC, HMBC spectra in $\mathrm{C}_{5} \mathrm{D}_{5} \mathrm{~N}$ for compounds $\mathbf{1}$ and $\mathbf{3}$ and $\mathrm{CD}_{3} \mathrm{OD}$ for compound 2 at 500,300 and 125 and $75 \mathrm{MHz}$, respectively, using a AM 500 and 300 Bruker Spectrometers. Chemical shifts $\delta$ in ppm and coupling constants in Hz. EI, CI-MS: JMS-HX-110 with a data system.

Plant Material The plant Zygophyllum atriplicoides (Zygophyllaceae) was collected from Quetta, Balochistan, Pakistan, in 2002, and was identified by one of us (RBT). A voucher specimen (no. 1408) has been deposited at the herbarium of the Botany Department, Balochistan University, Quetta.

Extraction and Isolation The shade-dried whole plant $(20 \mathrm{~kg})$ was crushed and extracted with methanol at room temperature. The extract was evaporated to yield the residue $(100.5 \mathrm{~g})$. The whole residue was extracted with ethyl acetate, $n$-butanol and water. The butanolic extract $(50.3 \mathrm{~g})$ was subjected to column chromatography (CC) on silica gel using a gradient of methanol in $\mathrm{CHCl}_{3}$. The fractions eluted with $20-25 \%$ (A) and $35-40 \%$ (B) methanol in $\mathrm{CHCl}_{3}$ were then subjected to repeated flash chromatography on silica column provided subfraction A-1 and B-1 from fraction A and $\mathrm{B}$ respectively. The presence of one major spot of $\mathrm{A}$ and $\mathrm{B}$ were shown by TLC ( $n$-BuOH-AcOH- $\left.\mathrm{H}_{2} \mathrm{O} 12: 3: 5\right)$ and $\mathrm{MeOH}: \mathrm{CHCl}_{3}$ (25:75) along with impurities The fractions were then subjected on repeated column chromatography. Compound $\mathbf{1}$ was purified on using solvent system $\mathrm{MeOH}: \mathrm{CHCl}_{3}(18: 82)$.

Fraction B was first subjected on Sephadex using water and then by adding methanol in increasing order. Compound $\mathbf{2}$ was purified by column chromatography using solvent system $\mathrm{MeOH}: \mathrm{CHCl}_{3}(20: 80)$ and compound 3 by $\mathrm{MeOH}: \mathrm{CHCl}_{3}(16: 84)$.

Atriplicosaponin A (1): Crystalline compound $(25 \mathrm{mg}), \mathrm{mp} 215-217^{\circ} \mathrm{C}$, $R f=0.49, \mathrm{CHCl}_{3}: \mathrm{MeOH}(0.49)$, (BAW), 0.39 (BEW), 0.30 (15: 85, HOAcwater); UV- $\lambda_{\max }(\mathrm{MeOH}): 199,205,268,315 \mathrm{~nm}$. IR $v_{\max }(\mathrm{KBr}) 3400(\mathrm{OH})$, $2927(\mathrm{CH}), 2856(\mathrm{C}=\mathrm{C}), 1700(\mathrm{C}=\mathrm{O}), 1027-1130(O$-glycosidic linkage $)$ and $825 \mathrm{~cm}^{-1} ;[\alpha]_{\mathrm{D}}^{25}+40^{\circ}(c=0.02, \mathrm{MeOH})$, EI-MS; $m / z$ 458, Positive FAB MS: $m / z 767$, Negative FAB-MS $m / z 765,{ }^{1} \mathrm{H}-\mathrm{NMR}\left(\mathrm{C}_{5} \mathrm{D}_{5} \mathrm{~N}, 500 \mathrm{MHz}\right)$ and ${ }^{13} \mathrm{C}$-NMR data: see Table 1.

Recrystallization of Compound 1: Methanol was heated to boil. Compound 1 was placed in an Erlenmeyer flask. Small amount of the hot methanol was poured into the flask containing the compound. The flask was swirled to dissolve compound. Then the flask was kept on the steam bath to keep the solution warm. When the compound was all in solution the flask was set on the bench top without disturbance. After a while, crystals were appeared in the flask. Now the flask was placed in an ice bath to finish the crystallization process. The crystals were filtered from the solution through vacuum filtration. After filtration they were scraped on the watch glass for drying.

Acid hydrolysis of Compound 1: Compound $1(10 \mathrm{mg})$ was hydrolyzed with $2 \mathrm{M} \mathrm{HCl}$ in aqueous methanol $(10 \mathrm{ml})$ at $100^{\circ} \mathrm{C}$ for $3 \mathrm{~h}$. The methanol was evaporated under reduced pressure and the mixture diluted with water and extracted with EtOAc. The EtOAc and water layers were evaporated under reduced pressure. The EtOAc layer contains aglycone and water layer contain sugars. The spectral data of aglycone was analyzed with the reported data of oleanane triterpenoid which led to the identification of aglycone as hederagenin. ${ }^{5,7)}$ The sugars were identified by comparision with authentic samples of glucose and xylose through paper chromatography as well as on silica gel TLC using solvent system as EtOAc: $\mathrm{MeOH}: \mathrm{HOAc}: \mathrm{H}_{2} \mathrm{O}$ $(11: 2: 2: 2)$ followed by spraying with sugar reagent (orcinol, ferric chloride and sulphuric acid) ${ }^{177}$ and heating.

Methylation of Compound 1: Compound $1(5.0 \mathrm{mg})$ in methanol was treated with excess diazomethane and the whole reaction mixture was allowed to stand for $12 \mathrm{~h}$. Removal of the solvent under reduced pressure gave its methyl ester.

Atriplicosaponin B (2): Crystalline compound $(20 \mathrm{mg}), \mathrm{mp} 215-217^{\circ} \mathrm{C}$, $R f=0.52$, (BAW), $\mathrm{CHCl}_{3}: \mathrm{MeOH}$ (0.49), 0.41 (BEW), 0.29 (15:85, HOAc-water); UV- $\lambda_{\max }(\mathrm{MeOH}): 195.8,199.0,205.8$ and 278.4. IR $v_{\max }$ $(\mathrm{KBr}) 3449.7(\mathrm{OH}), 2926(\mathrm{CH}), 2854(\mathrm{C}=\mathrm{C}), 1256(\mathrm{C}-\mathrm{O}), 1027-1130(\mathrm{O}-$ glycosidic linkage $)$ and $803 \mathrm{~cm}^{-1} ;[\alpha]_{\mathrm{D}}^{25}+10.26^{\circ}(c=0.02, \mathrm{MeOH})$, EI-MS; $m / z$ 442, Positiv FAB-MS: $m / z$ 832, Negative FAB-MS $m / z$ 830, ${ }^{1} \mathrm{H}-\mathrm{NMR}$ $\left(\mathrm{CD}_{3} \mathrm{OD}, 300 \mathrm{MHz}\right)$ and ${ }^{13} \mathrm{C}-\mathrm{NMR}$ data see Table 1.

Acid Hydrolysis of Compound 2: Compound $2(5 \mathrm{mg})$ was dissolved in $5 \mathrm{ml} 10 \% \mathrm{H}_{2} \mathrm{SO}_{4}$-dioxane $(1: 1)$ and refluxed for $3.5 \mathrm{~h}$ at $100{ }^{\circ} \mathrm{C}$. The reaction mixture was diluted with water and extracted with $\mathrm{CHCl}_{3}$. The aqueous layer was neutralized with $\mathrm{KHCO}_{3}$ and glucose was identified by the same procedure described for compound $\mathbf{1}$ while the assignments of chemical shifts of quinovose were based on the spectral data reported in literature. ${ }^{3)}$ The $\mathrm{CHCl}_{3}$ layer yielded aglycone which was identified as 27 -hydroxyursane by comparing with spectral data reported in literature. ${ }^{15)}$

3- $O$ - $[\beta$-D-Glucopyranosyl]- $\beta$-sitosterol (3): Crystalline compound (21 mg), mp 287-289 ${ }^{\circ} \mathrm{C}, R f=0.50$, (BAW), $\mathrm{CHCl}_{3}: \mathrm{MeOH}(0.47), 0.38$ (BEW), 0.26 (15:85, HOAc-water); IR $v_{\max }(\mathrm{KBr}) 3400(\mathrm{OH}), 2920,2840$ $(\mathrm{CH})$ and 1027-1130 (O-glycosidic linkage); Negative FAB-MS m/z 575.

Acid Hydrolysis of Compound 3: Compound $3(10 \mathrm{mg})$ was hydrolyzed with $2 \mathrm{M} \mathrm{HCl}$ in aqueous methanol $(10 \mathrm{ml})$ at $100^{\circ} \mathrm{C}$ for $3 \mathrm{~h}$. The methanol was evaporated under reduced pressure and the mixture diluted with water and extracted with EtOAc. The EtOAc and water layers were evaporated under reduced pressure. The EtOAc layer contains aglycone and water layer contain sugars. The aglycone was identified as sitosterol through comparison of its spectral data reported in literature. ${ }^{16)}$ The sugar was identified by comparision with authentic sample of glucose through paper chromatography as 
well as on silica gel TLC same as described for compound $\mathbf{1}$.

\section{References}

1) Nasir E., Ali S. I., "Flora of Pakistan," No. 76, Fakhri Printing Press, Karachi, 1972, pp. 27-35.

2) Li C.-J., Elgamal M. H., Sharker K. H., Ahmed A. A., Mabry T.-J., Nat. Prod. Lett., 8, 281-284 (1996).

3) Elgamal H. A., Elgamal K. H., Sharker K. H., Pollamann K., Seifert K., Phytochemistry, 40, 1233-1236 (1995).

4) Hassanean H. A., Doesky E. K., Phytochemistry, 31, 3293-3294 (1992).

5) Li X.-C., Wang D.-Z., Wu S.-G., Yang C. R., Phytochemistry, 29, $595-599$ (1990).

6) Heinzmann B. M., Schenkel E. P., J. Nat. Prod., 58, 1419-1422 (1995).

7) Tori K., Seo S., Shimaoka A., Tomita Y., Tetrahedron Lett., 1974, 4227-4230 (1974).

8) Ahmad V. U., Saba N., Pak. J. Sci. Ind. Res., 36, 54-56 (1993).

9) Buckingham J., "Dictionary of Organic Compounds," Vol. 3, Chapman and Hall, New York, 1985, p. 164.

10) Gorin P. A. J., Mazurek M., Can. J. Chem., 53, 1212-1223 (1975).

11) Lanzetta R., Laonigro G., Parrin M., Can. J. Chem., 62, 2874-2878 (1984).

12) Atta-ur-Rahman, "One and Two Dimensional NMR Spectroscopy,” Elsevier, Amsterdam, 1989.

13) Hidaka K., Ito M., Matsuda Y., Kohda H., Yamasaki K., Yamahara J., Chisaka T., Kawakami Y., Sato T., Kagei K., Chem. Pharm. Bull., 35, 524-529 (1987).

14) Ohashi K., Kojima H., Tanikawa T., Okumara Y., Kawazoe K., Tatara N., Shibuya H., Kitagawa I., Chem. Pharm. Bull., 42, 1596-1600 (1994).

15) Siddiqui B. S., Firdous, Begum S., Phytochemistry, 52, 1111-1115 (1999).

16) Sakakibara J., Kaiya T., Fukuda H., Ohaki T., Phytochemistry, 22, 2553-2555 (1983).

17) Stahl E. (ed.), “Thin Layer Chromatography," 2nd ed., Springer Verlag, Berlin-Heidelberg-New York, 1969, p. 892. 